đều đảm bảo vô cảm tốt, thuận lợi cho thủ thuật. Sự hài lòng của thủ thuật viên gián tiếp đánh giá hiệu quả của việc sử dụng an thần.

Kết quả nghiên cứu của chúng tôi cũng phù hợp với kết quả nghiên cứu của Hoàng Ngọc Vinh[7] và của Nguyễn Quang Bình [6]. Propofol có tác dụng an thần, tăng tác dụng của thuốc giảm đau gây tê và làm mềm cơ nên thuận lợi cho thủ thuật chọc noãn.

Sự hài lòng của bệnh nhân và sử dụng lại cùng phương pháp: Kết quả ở biểu 5 . và biểu đồ 6. mức độ hài lòng của bệnh nhân ở 2 nhóm khác nhau không có ý nghĩa thống kê $(98,6 \%$ ở nhóm PCS và $98,4 \%$ ở nhóm $G M$ với $p>0,05$ ). Như vậy tác dụng an thần của propofol giúp cho bệnh nhân thoải mái, hợp tác tốt hơn trong khi làm thủ thuật, sự hài lòng của bệnh nhân là yếu tố khách quan đánh giá hiệu quả của phương pháp vô cảm. Kết quả của chúng tôi cũng phù hợp với Nguyễn Quang Bình [6]. Tỷ lệ bệnh nhân mong muốn được áp dụng cùng phương pháp vô cảm nếu phải chọc noãn lần sau ở 2 nhóm khác nhau không có ý nghĩa thông kê với $\mathrm{p}>0,05$ (95,8\% ở nhóm PCS và $97,6 \%$ ở nhóm $\mathrm{GM})$. Kết quả này của chúng tôi cũng phù hợp với các nghiên cứu trong nước và quốc tế. Điểu này cho thây phương pháp an thần do bệnh nhân tự điều khiển có hiệu quả tương đương với gây mề tĩnh mạch để chọc noãn.

\section{KẾT LUẬN}

Phương pháp an thần do bênh nhân tự điều khiển (PCS) bằng Propofol, phối hợp với gây tê cạnh cổ tử cung bằng lidocain trong chọc hút noãn có hiệu quả vô cảm tốt, giúp bệnh nhân giảm tình trạng an thần sâu, giảm lượng thuốc mê tiêu thụ, giảm thời gian hồi tỉnh và thời gian xuất viện so với nhóm gây mê tĩnh mạch thông thường.

\section{TÀI LIẸU THAM KHẢO}

1. Jain D, Kohli A, Gupta L, Bhadoria P, Anand R. Anaesthesia for In Vitro Fertilisation. Indian J Anaesth. 2009;53(4):408-413.

2. Kwan I, Wang R, Pearce E, Bhattacharya S. Pain relief for women undergoing oocyte retrieval for assisted reproduction. Cochrane Database Syst Rev. 2018;5:CD004829.

3. Hayes MF, Sacco AG, Savoy-Moore RT, Magyar DM, Endler GC, Moghissi KS. Effect of general anesthesia on fertilization and cleavage of human oocytes in vitro. Fertil Steril. 1987; 48(6): 975-981.

4. Botta G, D'Angelo A, D'Ari G, Merlino G, Chapman M, Grudzinskas G. Epidural anesthesia in an in vitro fertilization and embryo transfer program. J Assist Reprod Genet. 1995; 12(3):187-190.

5. Osborne GA, Rudkin GE, Jarvis DA, Young IG, Barlow J, Leppard PI. Intra-operative patientcontrolled sedation and patient attitude to control. A crossover comparison of patient preference for patient-controlled propofol and propofol by continuous infusion. Anaesthesia.

6. Nguyê̂n Quang Bình. Nghiên cứu phương pháp an thân bă̆ng propofol do bệnh nhân țư điều khiển trong phẫu thuật răng - LUẬN ÁN TIẾN SĨ. Published online 2012.

7 Hoàng Ngọc Vinh. Nghiên cứu hiệu quả an thần bằng propofol do bệnh nhân tự điều khiển trong hút thai. Luận văn Tiến sỹ y học Đại học Y Hà Nội. Published online 2016.

8. Trịnh Xuân Trường (2015), Chương HV, Thạch NN, Kiên NT, Khoa NV. Gây mê Propofol chọc hút noắn và Fentanyl trong chọc hút noãn.

\title{
ĐĂC ĐIỂM TỔN THƯƠNG TRÊN CẮT LỚP VI TÍNH Ở BÊNH NHÂN GÃY MŨI SÀNG Ổ MẮT TẠI BỆNH VIỆN HŨ̃U NGHI VIỆT ĐỨC
}

\section{TÓM TẮT}

Mục tiêu: Nghiên cứu này được thực hiện nhằm mô tả các đặc điểm tổn thương trền $\mathrm{CLVT}$ của nhóm bệnh nhân được điều trị tại Khoa Phẫu thuật Hàm mặt-Tạo hình- Thẩm mỹ, Bệnh viện Hữu nghị Việt

\footnotetext{
IViện Đào Tạo Răng Hàm Mặt, Trường Đại học Y Hà Nội Bệnh viện Hữu nghi Việt Đức

Chịu trách nhiệm chính: Phan Văn Anh

Email: superbio1995@gmail.com

Ngày nhận bài: 5.7.2021

Ngày phản biện khoa học: 30.8.2021

Ngày duyệt bài: 8.9.2021
}

\section{Phan Văn Anh ${ }^{1}$, Nguyễn Hồng Hà ${ }^{2}$, Lê Văn $\mathrm{Nam}^{2}$}

Đức. Qua đó, góp phân hỗ trơ các bác sĩ trong việc chẩn đoán và lên kế hoạch điều trị cho những bệnh nhân gãy MSOM. Đối tượng và phương pháp: Nghiên cứu mô tả chùm ca bệnh dựa trên phim CLVT ở 43 bệnh nhân gãy MSOM được điều trị từ thàng 01/2020 đến tháng 04/2021 tại Khoa Hàm mặt- Tạo hình- Thẩm mỹ, Bệnh viện Hữu nghị Việt Đức. Dùng phần mềm SPSS để phân tích số liệu thống kê. Kết quả: Trong số 43 bệnh nhân, có 37 bệnh nhân (86\%) có tổn thương khớp trán - xương hàm trên, $100 \%$ có tổn thương khuyết lệ - bờ dưới ổ mắt, 33 bệnh nhân có tổn thương thành trong ổ mắt $(76,7 \%)$, tổn thương xương chính mũi thây ở 30 bệnh nhân $(69,8 \%), 34$ bệnh nhân có tổn thương vách ngăn $(79,1 \%), 42$ bệnh nhân có tụ dịch xoang sàng $(97,7 \%)$ và 14 bệnh 
nhân có võ các thành xoang trán $(32,6 \%)$. Tỷ lệ tổn thương theo typ I là hay găp nhất $(65,1 \%)$, tiếp đến là typ II $(30,2 \%)$, ít gặp nhất là typ III $(4,7 \%)$. Tỷ lệ gãy XHT là cao nhất 74,4\%. CTSN chiếm 44,2\%. Gãy GMCT và XHD gặp ít hơn với tỷ lệ lần lượt là $27,9 \%$ và 16,3\%. Kết luận: Phim CLVT là tiêu chuẩn vàng để chẩn đoán gãy MSOM. Bên cạnh đó còn giúp bác sĩ nhanh chóng phát hiện các tổn thương kèm theo như gãy các xương mặt, chấn thướng sọ não. Qua đó, nó trở thành công cự đắc lực hỗ trợ phẫu thuật viên lên kế hoạch điều trị một cách toàn diện để đạt hiệu quả tốt nhất, giảm thiểu các biến chứng xảy ra .

Tư khóa: mũi sàng ổ mắt, cắt lớp vi tính, võ thành xoang trán, tắc nghẽn đường thở.

\section{SUMMARY}

CHARACTERISTICS OF LESIONS ON COMPUTER TOMOGRAPHY IN PATIENTS WITH NASO ORBITO ETHMOID FRACTURE AT VIET DUC UNIVERSITY HOSPITAL

Objectives: Description of lesions on Computer Tomography (CT) in patients at Viet Duc University Hospital with Naso Orbito Ethmoid fracture (NOE), to provide information for diagnosis and treatment planning. Subjects and method: The cross sectional descriptive study of 43 patients with NOE fracture were treated at the Department of Maxillofacial - Plastic and Aesthetic Surgery, Viet Duc University Hospital from 01/2020 to 04/2021. The data were statistically analyzedby SPSS software. Results: In 43 patients, 37 patients $(86 \%)$ had fronto maxillary joint damage, $100 \%$ had lacrima-infraorbital margin lesions, 33 patients had medial orbital wall lesions $(76,7 \%)$, nasal bones fracture were founded in 30 patients $(69,8 \%), 34$ patients with septal fracture $(79,1 \%), 42$ patients with ethmoid sinus lesions $(97,7 \%), 14$ patients $(32,6 \%)$ with frontal sinus walls fracture. The rate of lesions according to type $I$ is the most common (65.1\%), followed by type II (30.2\%), the least common is type III $(4.7 \%)$. The rate of maxillary fracture is the highest at $74.4 \%$. Traumatic brain injuries for $44.2 \%$. Zygomatic complex and mandibular fractures are less common with the rate of $27.9 \%$, respectively; $16.3 \%$. Conclusion: CT is the gold standard for diagnosing NOE fracture. Besides, it also helps doctors quickly detect accompanying injuries such as facial bones fractures, traumatic brain injuries. Thereby, becoming an effective tool to help doctors plan a comprehensive treatment to achieve the best effect, minimizing complications.

Keywords: Naso Orbito Ethmoid, Computer Tomography, frontal sinus walls fracture, obstruction of the nasal airway.

\section{I. ĐĂT VẤN ĐỀ}

MSOM là một cấu trúc giải phẫu tinh vi, phức tạp theo ba chiêu trong không gian nên gãy xương vùng này luôn là một thách thức lớn trong chân thương vùng hàm mặt ${ }^{1,2}$. Sự có mặt của cấu trúc này và phần mềm phủ bên ngoài tạo nên sự hài hòa cho khuôn mặt. Các nghiên cứu cho thấy $5 \%$ chấn thương hàm mặt liên quan tới gãy $\mathrm{MSOM}^{3}$. Những tổn thương xảy ra ở này nhất là vùng liên quan đến điểm bám của dây chằng góc mắt trong thường gây ra những ảnh hưởng về cả chức năng lẫn thẩm mỹ ${ }^{4}$. Hơn nữa, cấu trúc này còn có sự liên quan mật thiết với sọ não và ổ mắt. Vì thế, khi nghi ngờ có tổn thương cấu trúc này chúng ta cần tiến hành thăm khám lâm sàng kĩ càng và sử dụng các phương tiên chẩn đoán hình ảnh để hỗ trợ tối đa trong chẩn đoán ${ }^{5}$. Về mặt lâm sàng rất khó để thực hiện thăm khám, sờ nắn do phù nề, đau đớn của bệnh nhân ${ }^{4}$. Trong thực tế, với sự phát triển mạnh mẽ của kĩ thuật chụp CLVT cho ta những hình ảnh sắc nét và chi tiết từ những tổn thương nhỏ nhất ${ }^{1}$. Cho nên, CLVT được coi như là tiêu chuẩn vàng để chẩn đoán xác định các trường hợp gãy MSOM. Để đưa ra một chẩn đoán chính xác chúng ta cần khảo sát một cách toàn diện các tổn thương theo 3 chiều không gian, có giá trị nhất là trên 2 lát cắt: Lát cắt ngang (Axial), lát đứng ngang (Coronal) kết hợp dựng hình 3D. Manson và Markowizt đã phân loại gãy MSOM thành 3 type dựa vào hình thái tổn thương của mảnh trung tâm (Mảnh trung gian trán-hàm trên). Type I: Tổn thương là mảnh trung gian bị di lệch nhưng không võ vụn, không tổn thương đến mào lệ nơi dây chằng khóe mắt trong bám. Type II: Mảnh trung gian bị võ thành nhiêu mảnh nhưng chưa xâm phạm đến vị trí bám của dây chằng khóe mắt trong. Type III: Mảnh trung gian bị vỡ thành nhiều mảnh và lan đến hố lệ, dây chằng khóe mắt trong mất điểm bám, loại này thường cần kết hợp chặt chẽ với khám lâm sàng để chẩn đoán phân loại ${ }^{1}$. Không dừng lại ở đó, CLVT còn là phương tiện hố trợ đắc lực các phẫu thuật viên trong lên kể hoạch điêu trị bệnh nhân gãy MSOM nhằm phục hồi tối đa về giải phẫu, chức năng và thẩm mỹ cho bệnh nhân $2,4,6$.

Hiện tại ở nước ta nói chung hay Bệnh viện Việt Đức nói riêng các nghiên cứu về đặc điểm tổn thương của gãy MSOM trên CLVT còn rất ít và chưa đầy đủ. Nghiên cứu này được thực hiện nhằm mô tả các đặc điểm tổn thương trên CLVT của nhóm bệnh nhần được điều trị tại Khoa Phẫu thuật Hàm mặt-Tạo hình- Thẩm mỹ், Bệnh viện Hưuu nghị Việt Đức. Qua đó, góp phần hổ trợ các bác sĩ trong việc chẩn đoán và lên kế hoạch điều trị cho những bệnh nhân gãy MSOM.

\section{II. ĐỐI TƯỢNG VÀ PHƯƠNG PHÁP NGHIÊN CỨU}

2.1. Đối tượng nghiên cứu. Phim CLVT của những bệnh nhẩn được chẩn đoán và điều trị các chấn thương tầng giữa mặt có tổn thương MSOM tại Bệnh viện Hữu nghị Việt Đức, từ năm 2020 
đến năm 2021.

Phương pháp chọn mẫu thuận tiện. Như vậy, chúng tôi chọn được cỡ mấu là 43 bệnh nhần đồng ý tham gia nghiên cứu tại Bệnh viện Hữu nghị Việt Đức thỏa mãn các điêu kiện: Bệnh nhân có chẩn đoán gãy MSOM trên phim CLVT, bệnh nhân đã được điều trị ổn định chấn thương sọ não và các chấn thương khác.

\subsection{Phương pháp nghiên cứu}

- Thiết kế nghiên cứu: Là một nghiên cứu mô tả chùm ca bệnh gồm mẫu hồi cứu và tiến cứu.

- Phương tiện nghiên cứu: Máy chụp cắt lớp vi tính đa dãy, hồ sơ bệnh án, bệnh án mẫu, máy tính xách tay, phần mềm thống kê SPSS 20.0 để phân tích và xử lý số liệu.

- Các bước tiến hành:

Bước 1: Các bệnh nhân được chụp cắt lớp vi tính hàm mặt đa dãy để khảo sát tổn thương.

Bước 2: Tiến hành dựng hình 3D từ các lát cắt.
Bước 3: Xác định các vị trí tổn thương trên phim cắt lớp vi tính của MSOM dựa trên lát cắt ngang (Axial), lát đứng ngang (Coronal) và dựng hình 3D.

- Các tổn thương có liên quan trong gãy MSOM bao gồm: Đường gãy khớp xương tránhàm trên, đường gãy khớp bờ khuyết lệ - bờ dưới ổ mắt, đường gãy thành trong ổ mắt, võ thành xoang trán, các đường gãy xương mũi, tổn thương vách ngăn mũi, tụ dịch trong xoang sàng.

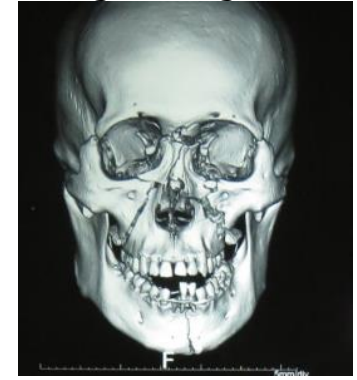

Hình 1: Hình ảnh tái tạo 3D trong chup cắt lớp vi tính hàm mặt.

- Các tổn thương vùng sọ, mặt kèm theo như: gãy xương hàm trên $(\mathrm{XHT})$, gò má cung tiếp (GMCT), xương hàm dưới (XHD) và chấn thương so não (CTSN).
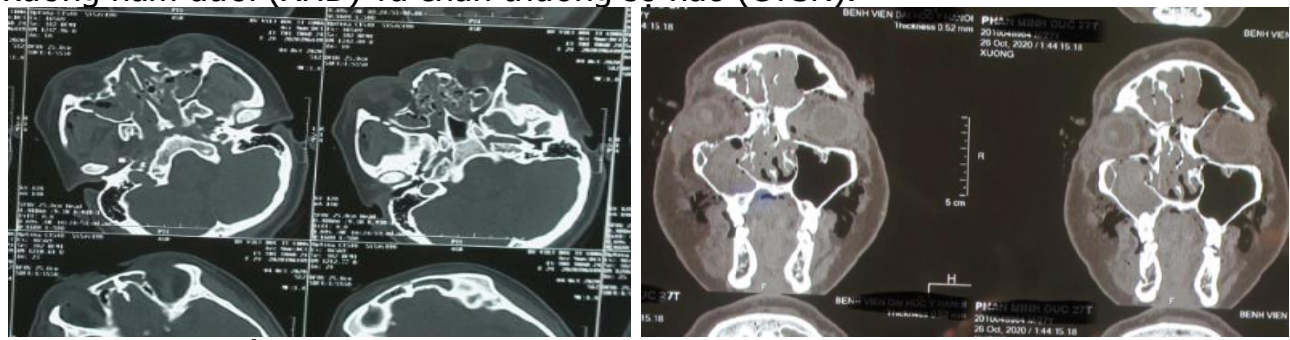

Hình 2: Hinh ảnh tôn thương trên lát cắt ngang (Axial) và trên lát cắt đứng ngang (Coronal).

- Xử lý số liệu: Dùng phần mềm thống kê SPSS 20.0 để nhập và xử lý số liệu: Tính các tỷ lệ \%, so sánh với tỷ lệ cho trước.

- Đạo đức nghiền cứu: Đối tượng nghiên cứu được giải thích rõ về mục đích nghiên cứu, trách nhiệm của người nghiên cứu, trách nhiệm và quyền lợi của người tham gia nghiên cứu. Nghiên cứu chỉ được tiến hành trên những đối tượng tự nguyện tham gia. Toàn bộ thông tin thu thập được bảo mật và chỉ phục vụ cho mục đích nghiên cứu.

\section{KẾT QUẢ NGHIÊN CứU}

Sau khi tiến hành nghiên cứu trên phim CLVT đa dãy 43 bệnh nhân được chẩn đoán gãy MSOM, chúng tôi thu được kết quả sau:

3.1. Đăc điểm tổn thương trên phim CLVT của MSOM

Bảng 1. Đặc điểm các tổn thương liên quan của gãy MSOM trên CLVT đa dãy.

\begin{tabular}{|c|c|c|}
\hline Tốn thương & $\mathbf{n}$ & $\mathbf{\%}$ \\
\hline $\begin{array}{c}\text { Đường gãy khớp xương } \\
\text { trán - XHT }\end{array}$ & 37 & $86 \%$ \\
\hline
\end{tabular}

\begin{tabular}{|c|c|c|}
\hline $\begin{array}{c}\text { Đường gãy khuyết lê - } \\
\text { bỡ dưới ổ mắt }\end{array}$ & 43 & $100 \%$ \\
\hline Đường gãy thành trong ố mắt & 33 & $76,7 \%$ \\
\hline Vỡ thành xoang trán & 14 & $32,6 \%$ \\
\hline Các đường gãy xương mũi & 30 & $69,8 \%$ \\
\hline Tốn thương vách ngăn mũi & 34 & $79,1 \%$ \\
\hline Tụ dịch trong xoang sàng & 42 & $97,7 \%$ \\
\hline n & $\mathbf{4 3}$ & $\mathbf{1 0 0 \%}$ \\
\hline
\end{tabular}

Qua thống kê, chúng ta thấy được các tổn thương thây được nhiêuu nhất trên CLVT là đường gãy khuyết lệ-bờ dưới ổ mắt $(100 \%)$, hình ảnh tụ dịch trong xoang sàng $(97,7 \%)$. Tôn thương vơ thành xoang trán là một tổn thương đi kèm không thuộc cấu trúc MSOM và có tỉ lệ gặp thấp nhất $(32,6 \%)$.

\subsection{Phân loại tốn thương theo Manson}

- Markowirzt

Bảng 2. Phân loại theo Manson - Markowirzt

\begin{tabular}{|c|c|c|}
\hline Phân loại & $\mathbf{n}$ & $\mathbf{\%}$ \\
\hline Typ I & 28 & $65,1 \%$ \\
\hline Typ II & 13 & $30,2 \%$ \\
\hline Typ III & 2 & $4,7 \%$ \\
\hline N & 43 & $100 \%$ \\
\hline \multicolumn{2}{|r}{}
\end{tabular}


Tỷ lê tổn thương theo typ I là hay găp nhất $(65,1 \%)$, tiếp đến là typ II $(30,2 \%)$, it gặp nhất là typ III $(4,7 \%)$.

3.3. Các chấn thương ở vùng sọ và mặt kèm theo

Bảng 3. Các chấn thương ở vùng sọ và mặt kèm theo

\begin{tabular}{|c|c|c|}
\hline Tốn thương & $\mathbf{n}$ & $\mathbf{\%}$ \\
\hline Xương hàm trên & 32 & $74,4 \%$ \\
\hline GM-CT & 12 & $27,9 \%$ \\
\hline XHD & 7 & $16,3 \%$ \\
\hline CTSN & 19 & $44,2 \%$ \\
\hline $\mathbf{N}$ & $\mathbf{4 3}$ & $\mathbf{1 0 0} \%$ \\
\hline
\end{tabular}

Tỷ lệ gãy XHT là cao nhất $74,4 \%$. CTSN chiếm 44,2\%. Gãy GMCT và XHD gặp ít hơn với tỷ lệ lần lượt là 27,9\%; 16,3\%.

\section{BÀN LUÂN}

Nghiên cứu của chúng tôi bao gồm 43 bệnh nhân được chẩn đoán gãy MSOM được khảo sát các tổn thương có liên quan trên phim CLVT đa dãy. Các tổn thương được nghiên cứu là những tổn thương cơ bản nhất, đặc trưng nhất của gãy MSOM. Chúng ta thấy rằng các tổn thương liên quan đến phần ổ mắt (khớp trán-hàm trên, khuyết lệ-bờ dưới ổ mắt, thành trong ổ mắt) gặp với tỷ lệ $100 \%$. Tỷ lệ này là cao hơn so với một nghiên cứu của Cruse CW và cộng sự năm 1980 $(94 \%)^{7}$. Hình ảnh tụ dịch trong xoang sàng là một tổn thương phổ biến với tỷ lệ gặp là rất cao $(97,7 \%)$.

Tổn thương xương chính mũi là một tổn thương gặp thường xuyên $(69,8 \%)$ và đáng được lưu tâm vì nó có những tác động nhất định đến việc lên kế hoạch điều trị của các phẫu thuật viên, có cần tiến hành phẫu thuật đặt nẹp hay chỉ cần nắn chỉnh xương chính mũi mà không cần đặt nẹp để tái tạo lại hình thể mũi. Trong một nghiên cứu khác của Nguyễn Hùng Thắng năm 2017 cho thây tỷ lê tổn thương ở xương chính mũi là cao hơn rất nhiều $(93,5 \%)^{8}$. Bên cạnh đó tổn thương vách ngăn mũi là một tổn thương đơn độc hay gặp nhưng dễ bị bỏ sót trong chẩn đoán $(79,1 \%)$. Đây là một trong những nguyên nhân gây ngạt tắc mũi mạn tính sau gãy MSOM ở các bệnh nhân không được điều trị triệt để. Leander Dubois và các cộng sự năm 2020 đã chỉ ra rằng lưu lượng đỉnh thở ra trong một phút giảm đáng kể (còn $20 \%$ so với sau điêu trị) trên bệnh nhân tổn thương vách ngăn mũi trước điều trị̉. Vậy nên việc đánh giá tổn thương này trên các lát cắt Axial và Coronal rất quan trọng và giúp đem lại kết quả điều trị là rất khả quan.

Tổn thương các thành của xoang trán chiếm tỷ lệ $32,6 \%$, tỷ lệ này không có sự khác biệt nhiều so với tỉ lệ Cruse CW đưa ra là $24 \%{ }^{7}$. Tỷ lệ bệnh nhân có CTSN trong nghiên cứu chiếm $44,2 \%$. Đây là những tổn thương không thuộc cấu trúc của MSOM nhưng có liên quan mật thiết và ảnh hưởng đến thái độ xử trí ban đâu cũng như quyết định kế hoạch điều trị của bác sĩ. Trong trường hợp võ thành sau có kèm rách màng não cứng gây ra rò dịch não tủy hay chấn thương sọ não thì việc kết hợp điêu trị với khoa Phẫu thuẩt Thần Kinh là rất cần thiết. Đối với trường hợp vỡ thành trước xoang trán có thì phẫu thuật tiến hành theo đường mổ Coronal để cùng lúc tiếp cận được tổn thương ở MSOM và xương trán một cách nhanh chóng.

Theo phân loại của Manson-Markowirzt chúng ta có tỷ lệ các typ I,II,III lần lượt 65,1\%; 30,2\%; $4,7 \%$. Tỷ lệ này khá tương đồng với nghiên cứu của Nguyễn Hùng Thắng năm $2017^{\circ}$. Phân loại giúp chúng ta có thể hình dung được hình thái tổn thương MSOM môt cách dể dàng và nhanh chóng nên được phổ biến trên toàn thế giới. Trong số các chấn thương vùng mặt kèm theo ta thấy hay gă̆p hơn cả là gãy XHT với tỷ lê $74,4 \%$ tương đương với nghiên cứu của Cruse $\mathrm{CW}^{7}$. Tỷ lệ gãy XHD là $16,3 \%$ không có sự khác biệt nhiều với Cruse là $25 \% 7$. Tỷ lệ gãy GMCT được ghi nhận là $27,9 \%$ tỷ lệ này ít hơn nghiên cứu của Cultrara đưa ra $(44,4 \%)^{9}$.

\section{KẾT LUÂ̂N}

Gãy MSOM là một tổn thương phức tạp nằm ở phần trên tâng giữa mặt, nếu chỉ dựa vào thăm khám lâm sàng và $X$ quang thường quy thì rất dễ bỏ sót tổn thương. Nghiên cứu được thực hiện trên nhóm bệnh nhân này nhằm khẳng định CLVT là tiêu chuẩn vàng để chẩn đoán gãy MSOM. Bên cạnh đó còn giúp bác sĩ nhanh chóng phát hiện các tổn thương kèm theo như gãy các xương mặt, chấn thương sọ não. Qua đó, nó trở thành công cụ đắc lực hỗ trợ phẫu thuật viên lên kế hoach điều trị một cách toàn diện để đạt hiệu quả tốt nhất, giảm thiểu biến chứng xảy ra trong và sau điêu trị.

\section{TÀI LIÊU THAM KHẢO}

1. Hopper RA, Salemy S, Sze RW. Diagnosis of midface fractures with CT: what the surgeon needs to know. Radiogr Rev Publ Radiol Soc N Am Inc. 2006;26(3):783-793. doi:10.1148/rg.263045710

2. Andrews BT, Surek CC, Tanna N, Bradley JP. Utilization of computed tomography image-guided navigation in orbit fracture repair. The Laryngoscope. 2013;123(6):1389-1393. doi:10.1002/ lary.23729

3. Dubois L, Dalmeijer SWR, Steenen SA, Gooris PJ. Obstruction of the Nasal Airway in NOE 
Fractures. Craniomaxillofacial Trauma Reconstr Open. 2020;5:2472751220940130. doi:10.1177/2472751220940130

4. Onișor-Gligor F, Tent PA, Bran S, Juncar $M$. A Naso-Orbito-Ethmoid (NOE) Fracture Associated with Bilateral Anterior and Posterior Frontal Sinus Wall Fractures Caused by a Horse Kick-Case Report and Short Literature Review. Medicina (Mex). 2019; 55(11):731. doi:10.3390/ medicina5 5110731

5. Wei J-J, Tang Z-L, Liu L, Liao X-J, Yu Y-B, Jing $W$. The management of naso-orbital-ethmoid (NOE) fractures. Chin J Traumatol. 2015; 18(5):296-301. doi:10.1016/j.cjtee.2015.07.006

6. Potter JK, Muzaffar AR, Ellis E, Rohrich RJ, Hackney FL. Aesthetic management of the nasal component of naso-orbital ethmoid fractures. Plast Reconstr Surg. 2006;117(1):10e-18e. doi:10.1097/01.prs.0000195081.39771.57

7. Cruse CW, Blevins PK, Luce EA. Naso-ethmoidorbital fractures. J Trauma. 1980;20(7):551-556. doi:10,1097/00005373-198007000-00003

8. Nguyễn Hùng Thẳng, Vũ Ngọc Lâm, Lê Đức Tuấn (2014), "Nghiến cứu đặc điểm lâm sàng gãy phức hợp mũi-sàng-ổ mắt một bên", Tạp chí Y Dược lâm sàng 108, (6), tr. 102-106.

9. Cultrara A, Turk JB, Har-EI G. Midfacial Degloving Approach for Repair of Naso-OrbitalEthmoid and Midfacial Fractures. Arch Facial Plast Surg. Published online March 1, 2004. doi:10.1001/archfaci.6.2.133

\section{GIÁ TRI CỦA PHÂN LOAI IOTA ADNEX TRONG ĐÁNH GIÁ KHỐI U BUỒNG TRỨNG BẰNG SIÊU ÂM TẠI BỆNH VIỆN K}

\author{
Nguyễn Duy Thái ${ }^{1}$, Dương Đức Hữu' ${ }^{1}$, \\ Hoàng Thị Vi Hương ${ }^{1}$, Ngô Đức Anh ${ }^{1}$, Nguyễn Văn Thi ${ }^{1}$

\section{SUMMARY \\ VALUE OF THE IOTA ADNEX CLASSIFICATION IN THE ULTRASOUND ASSESSMENT OF OVARIAN TUMORS AT K HOSPITAL} \\ Objectives: This study aim to evaluate the value
} TÓM TẮT

Mục tiêu: Nghiên cứu nhằm đánh giá giá trị của mô hình IOTA ADNEX trong siêu âm chẩn đoán mức độ lành tính - ác tính của khối u buồng trứng tại bệnh viện $K$. Đối tượng và phương pháp: Nghiền cứu được thực hiện trên 54 bệnh nhân trong khoảng thời gian từ tháng 12 năm 2020 đến tháng 05 năm 2021 tại bệnh viện $K$ với lâm sàng nghi ngờ u buồng trứng, được siêu âm trước phẫu thuật và thu thập số liệu theo mô hình IOTA ADNEX, được phẫu thuất với chẩn đoán sau phẫu thuât là u buồng trứng. Đối chiếu kết quả phẫu thuật, kết quả giải phẫu bệnh với mô hình IOTA ADNEX thu thập trước phẫu thuật. Từ đó đánh giá giá trị của mô hình IOTA ADNEX trong siêu âm chẩn đoán mức độ lành tính - ác tính u buồng trứng. Kết quả: Mô hình IOTA ADEX có CA 125 và mô hình IOTA ADNEX không có CA 125 có giá trịtốt trong chẩn đoán phân biệt u buồng trứng lành tính và ác tính với diện tích dưới đường cong ROC (Area under the curve - AUC) lần lướt là 0,977 và 0,968 . Ngưỡng cắt tối ưu của mô hình IOTA ADNEX có CA 125 và mô hình IOTA ADNEX không có CA125 lần lượt là 24,5 và 25,2 . Tại ngưỡng cắt tối ưu, cả hai mồ hình này đều có độ nhạy, độ đăc hiệu, giá trị dự báo dương tính, giá trị dự báo âm tính, độ chính xác lần lượt là 92,3\%, $96,8 \%, 96 \%, 93,8 \%, 94,7 \%$. Kết luận:Mô hình IOTA ADNEX có CA 125 và mô hình IOTA ADNEX không có CA 125 đều có giá trị cao và tương đồng trong chẩn đoán phân biệt u buồng trứng lành tính và ác tính ở bệnh viện K. Tư khóa: IOTA ADNEX, CA 125, u buồng trứng, siêu âm.

\section{${ }^{1}$ Bệnh viện $K$}

Chịu trách nhiệm chính: Nguyễn Duy Thái

Email: duythaibvk@gmail.com

Ngày nhận bài: 8.7.2021

Ngày phản biện khoa học: 31.8.2021

Ngày duyệt bài: 10.9.2021 of the IOTA ADNEX model in the diagnosis of benign malignant levels of ovarian tumors at $K$ hospital. Marterial and Methods: The propestive study was conducted on 54 patients from December 2020 to May 2021 at K hospital with clinical suspicion of ovarian tumor, were taken preoperative ultrasound and were collected data according to the IOTA ADNEX model, then were operated and diagnosed with ovarian tumor. The surgical and pathological results were compared with the IOTA ADNEX model data collected before surgery. Then the values of the IOTA ADNEX models in diagnosis ovarian tumors were evaluated. Results: Both the IOTA ADNEX model with CA 125 and the IOTA ADNEX model without CA 125 were very good for distinguishing between benign and malignant tumors with an Area under the curve (AUC) were 0,977 and 0,968 , respectively. The optimal cut - off point of the IOTA ADNEX model with CA 125 and the IOTA ADNEX model without CA 125 were 24,5 and 25,2 , respectively. At the optimal cut - off point, both predictive value, negative predictive value, accuracy of $92,3 \%, 96,8 \%, 96 \%, 93,8 \%, 94,7 \%$, respectively. Conclusion: Both the IOTA ADNEX model with CA 125 and the IOTA ADNEX model without CA 125 have high value and are similar in distinguishing between benign and malignant ovarian tumors at $K$ hospital.

Key words: IOTA ADNEX, CA 125, ovarian tumor, ultrasound.

\section{I. ĐặT VẤN ĐỀ}

U buồng trứng là một phát hiện phổ biến trong thực hành lâm sàng hàng ngày. ${ }^{1}$ Trong đó, two models had sensitivity, specificity, positive 